\title{
Cultural determinants: Addressing barriers to holistic diabetes care
}

\author{
Sandeep Sachdeva, Najam Khalique ${ }^{1}$, M. Athar Ansari ${ }^{1}$, Zulfia Khan ${ }^{1}$, Sunil Kumar Mishra, Gaurav Sharma ${ }^{2}$ \\ Department of Community Medicine, SN Medical College, Agra, Departments of ${ }^{1}$ Community Medicine and ${ }^{2}$ Physiology, Jawaharlal Nehru \\ Medical College, Aligarh Muslim University, Aligarh, Uttar Pradesh, India
}

\section{A B S T R A C T}

Background: Cultural beliefs and traditional practices nearly affect all aspects of diabetes care. Therefore, understanding its broader cultural context can serve as important background information for effective care for diabetes. Materials and Methods: We conducted this study to explore the cultural determinants in diabetes care and to propose a broad theoretical framework for cultural assessment in persons with diabetes. Explanatory Model Interview Catalog interviews of 25 diabetes persons were conducted. Results: We found that perception about diabetes is influenced by tradition, customs and ethos. Diabetes does not show early signs and therefore symptoms are usually ignored until they interfere with their day-to-day living. Following dietary advice was the most difficult part of diabetes care due to varied cultural barriers. Due to cultural reasons, diabetes is still not assigned due priority by the family. Health illiteracy and cost of care were important barriers for seeking care. Diabetics taking conventional treatment often used complementary treatment, which may be hazardous. Language was also considered a barrier for effective diabetes care. Females struggle more for receiving appropriate care for their diabetes due to social and cultural factors. Conclusion: Cultural assessment needs to be done at various stages - initial assessment, identification of cultural issues in care, planning for culturally relevant intervention and evaluation. This calls for focused elements relevant to the presenting problem, necessary intervention, and participatory evaluation. Cultural values, beliefs, customs, and family patterns may be used as clues for planning diabetes care. Such interventions are likely to bear significant impact on diabetes care in times to come.

Key words: Barriers for care, cultural assessment, cultural determinants, diabetes

\section{INTRODUCTION}

Globally, by the year 2025, the adult population will increase by $64 \%$ and prevalence of diabetes in adults will increase by $35 \%$. This will in turn increase the number of people with diabetes by around $122 \%$. Developed countries will have a $42 \%$ increase in number of people with diabetes. Developing countries are predicted to have an $82 \%$ increase in the adult population and $170 \%$ increase in the number of people with diabetes. ${ }^{[1]}$ India currently leads the world with 51 million people with diabetes and this number is

\begin{tabular}{|c|l|}
\hline \multicolumn{2}{|c|}{ Access this article online } \\
\hline Quick Response Code: & Website: \\
\hline & www.joshd.net \\
\hline & \\
\hline & \\
\hline
\end{tabular}

expected to increase to 87 million by 2030 , accounting for one-fifth of the world's population of diabetes. ${ }^{[2,3]}$ The past decade has thus witnessed a rapid increase in the prevalence of diabetes in India. ${ }^{[4]}$

Among diabetic patients, achieving optimal glycemic control requires them to take part in a complex set of tasks like adherence to dietary advice and medications, engagement in regular physical activity, quitting smoking, and monitoring blood glucose levels. ${ }^{[5]}$ Therefore, it is essential to place individuals and families in an appropriate context for diabetes prevention and care. Understanding the broader cultural context can serve as important background information for effective care for diabetes. ${ }^{[6]}$ Cultural beliefs and traditional practices affect nearly all aspects of the disease, like perception about diabetes, its assessment and diagnosis, care seeking behavior, expectation from providers, and so forth. Moreover, culture may influence diabetes self-management as well.

Corresponding Author: Dr. Sandeep Sachdeva, Department of Community Medicine, SN Medical College, Agra, Uttar Pradesh, India. E-mail: sandeepsemail@rediffmail.com 
Very few studies have explored the effect of cultural beliefs and attitudes toward diabetes prevention and care services. It would be important for diabetes care providers to understand cultural determinants in order to provide holistic care for people with diabetes. ${ }^{[7]}$ Therefore, we conducted this study to explore the cultural characteristicsrelated to diabetes mellitus in India and its potential influence on diabetes care. We also propose a broad theoretical framework for cultural assessment for people living with diabetes [Table 1].

\section{MATERIALS AND METHODS}

This qualitative study was conducted in rural western Uttar Pradesh (Agra) in the field practice areas of the Rural Health Training Centre, SN Medical College, Agra. Study participants were known cases of type 2 diabetes mellitus currently on treatment. For data collection, we used the Explanatory Model Interview Catalogue (EMIC) interviews of diabetic patients. EMIC, the progenitor of which is the famous anthropologist Arthur Kleinman refers to a framework of the semi-structured interview based on a particular operational formulation of the concept of illness explanatory models and a set of explanatory model interviews based on that framework. The EMIC approach is useful in studying the illness as well as understanding the social and cultural factors

\begin{tabular}{|c|c|c|}
\hline Phases & Goals & $\begin{array}{l}\text { Strategies/topics of } \\
\text { assessment }\end{array}$ \\
\hline $\begin{array}{l}\text { General } \\
\text { assessment }\end{array}$ & $\begin{array}{l}\text { To gain an overview } \\
\text { about the client } \\
\text { cultural issues } \\
\text { that need in-depth } \\
\text { assessment }\end{array}$ & $\begin{array}{l}\text { Ethnicity, acculturation, } \\
\text { religion, pattern, decision } \\
\text { making process, ability to } \\
\text { communicate and barriers }\end{array}$ \\
\hline $\begin{array}{l}\text { Problem } \\
\text { identification }\end{array}$ & $\begin{array}{l}\text { To assess cultural } \\
\text { information } \\
\text { specifically related } \\
\text { to clients presenting } \\
\text { complaints }\end{array}$ & $\begin{array}{l}\text { Clients' reason for accessing } \\
\text { care, stigma associated with } \\
\text { disease (if any), perception } \\
\text { regarding the cause of } \\
\text { problems, practices related } \\
\text { to treatment/complementary } \\
\text { treatment and knowledge } \\
\text { about future treatment }\end{array}$ \\
\hline $\begin{array}{l}\text { Planning for } \\
\text { intervention/ } \\
\text { care* }^{*}\end{array}$ & $\begin{array}{l}\text { To elicit detailed } \\
\text { cultural factors } \\
\text { that may influence } \\
\text { intervention or care } \\
\text { plan }\end{array}$ & $\begin{array}{l}\text { Clients' current and preferred } \\
\text { cultural beliefs related } \\
\text { to specific care needs or } \\
\text { intervention planned to deliver }\end{array}$ \\
\hline $\begin{array}{l}\text { Evaluation } \\
\text { of care or } \\
\text { intervention } \\
\text { delivered }\end{array}$ & $\begin{array}{l}\text { To plan for evaluation } \\
\text { of the intervention to } \\
\text { be delivered }\end{array}$ & $\begin{array}{l}\text { Patients and family views } \\
\text { regarding care or intervention } \\
\text { to be incorporated planned for } \\
\text { client, identifying and defining } \\
\text { preferred outcome measures } \\
\text { to be incorporated into the } \\
\text { evaluation }\end{array}$ \\
\hline
\end{tabular}

* Stands for indepth qualitative inputs affecting the course of the illness. ${ }^{[8]}$ We interviewed 25 adult patients ( 15 male and 10 female) of type 2 diabetes mellitus after an informed consent from each participant. Interviews were conducted by trained researchers in local language, each lasting about 35-45 $\mathrm{min}$. The sample was a convenience one. All interviews were recorded, with the consent from participants being interviewed. After the interviews, the recordings were transcribed into computer files. Care was taken to assure the respondents that they and the place of their work would not be identifiable in any subsequent report.

All interview transcripts were read by the researcher and coded in the style of a grounded theory approach for data analysis. Category headings were generated from the data and under these, all data were accounted for. Two independent researchers verified the seeming accuracy of the category system and after discussion with them; minor modifications were made to it. In the grounded theory literature, a good category system is said to have emerged from the data. ${ }^{[9]}$

\section{Findings}

Age of respondents range from 36 years to 62 years and all of them were from rural areas. Three male and two female participants were illiterate. All respondents were currently on the antidiabetic medications.

Respondents believed that the way in which they perceived the illness depended upon their tradition, customs and ethos, which were observed in their society since generations. Respondents also said that people mostly try home remedies for their illness, before going to a doctor.

If anyone is ill in our family we first try home treatment, like using turmeric and milk for cold, ginger for cough. We also use Ayurvedic medications (Indian system of medication). We go to the doctor only if our home treatment does not work.

It was also learned that, perceptions regarding the diabetes were also influenced by cultural factors. Respondents stated that illness, and particularly chronic illness like diabetes, which do not show sign and symptoms early in the stage of disease are usually ignored until it interferes with their day to day living. One respondent noted that.

Diabetes is not a disease because it does not show signs and it does not interfere with day to day work.

Almost all respondents said that, they were told by their doctors to modify their diet. However, many felt that this was the most difficult thing to follow and religion or 
cultural factors were the main barriers. One respondent said:

Sweets are prepared during festivals and it is a ritual to use sweets a Prasad (offerings shared with other devotees after prayer) which we cannot refuse.

Many felt that that it is cumbersome to prepare a separate meal for one person in the home. Preparing special food for oneself or for one person goes against the cultural ethos of providing for all family members impartially.

Respondents also found difficulty in having frequent meals at short intervals as advised by their providers. Most of them were of the habit of taking morning and evening tea and two meals in a day. One male respondent narrated.

I have to go to farm for work early in the morning, so mostly take morning tea and go to work. I carry my food with me for lunch, which I eat between 1 and 2 (pm) in the afternoon. Then $i$ take dinner at night when I am back home. People do not consider it a good thing to keep eating for the entire day (frequent meals).

Regarding diabetes care seeking behavior, we found that cultural factors influenced the access to health care delivery services in a significant way. Respondents said that many people were not aware about the available of diabetes care services and people also ignored the disease as it was not considered to be of sufficient priority by the family. Overall; health illiteracy and cost of care, particularly indirect cost of care, were important barriers for seeking care. One respondent said.

We feel why to go to doctors if we are not ill (not having signs and symptoms of illness). If we go to the hospital, we have to give an entire day. It also costs us 100 rupees to go to the hospital and doctors charge fees also.

It was also notable to learn that most of people with diabetes, who were on conventional treatment, also used other treatment, like home remedies or some Ayurvedic formulations (Indian system of medicine). Many respondents said this is a very common practice. One of the respondents mentioned-

I was diagnosed as diabetic 4 years back and since then I am taking the medication regularly. My uncle told me that diabetes is caused by excessive consumption of sweets, so consuming bitter things helps a lot. From the last 2 years, I am also taking Neem juice, which is bitter in taste along with the medication given by doctors.

Respondents observed that many times, it became difficult for them to understand what care providers were saying due to different language or too much use of English words during their conversation. As a result, people with diabetes, who sought care felt stressed and were not able to follow the correct advice. One respondent said.

Doctors are always in a hurry as there are more patients waiting for them. Many times, we do not follow what they say. Doctors use English words, which we do not understand.

Female respondents talked about the various social and cultural factors as a barrier to follow the dietary and care advice given by their providers. It was also noted that females ignore their own health and also lack sufficient support from family for care of their illness. One female respondent narrated:

I do not go for work. I am responsible for managing my home. I cook the food but the choice of food (to be cooked) is not mine. Usually, I cook what my children and husband like. I take care of everyone and therefore I do not get time for myself. I do not prepare meals as told to me by the nurse (health care provider) as my family does not like it. Usually I eat last, after my husband finishes therefore cannot eat on time as told to me by the doctor. I try to take medicine on time but sometimes I forget. My husband is busy with daily work, so he does not know what drugs I am taking for diabetes. He does not come with me to the hospital.

Males also agree with the female respondents' views regarding difficulties faced by them for taking care of themselves. One male respondent said.

Women usually eat last in the home; for them it is very difficult to follow the doctor's advice. The problem is more if there are grandparents in home (joint family) or if there are many members in the family.

It was also observed that female respondents were not aware of gestational diabetes. As a result they do not consider it important to check for blood sugar during pregnancy.

\section{DISCUSSION}

People negotiate and interpret culture in variable forms and in diverse contexts. Beliefs regarding illnesses and in particular, chronic illness like diabetes are greatly influenced by cultural norms in a significant way.

\section{Culture and health beliefs and practices}

Cultural factors and belief influences how people perceive their overall health, illness and practices related to it. ${ }^{[6,10]}$ Home treatment, self-medication or use of Ayurvedic 
herbs for treating illness is deep rooted in Indian culture. Ritual healings from spiritual healers are not uncommon. Ayurveda, the Indian system of medicine, which is culturally accepted in Indian community since ages, states that the persons are healthy till their bodily fluids are in the state of equilibrium or else the illnesses crop up. Diabetes has been referred in Ayurveda as a "Madhumeha" occurring due to inactivity, laziness, lack of exercise, excessive sleep and excessive use of yogurt, meat and soup of domestic, aquatic and marshy land animals, consumption of unmatured/nonaged grains, products of jaggery and sweets. ${ }^{[11]}$ However, what exactly constituted Ayurvedic medicines and what did not qualify being Ayurvedic remained a conjectural issue.

Cultural factors are responsible for the way in which the diabetes is perceived by the community, the manner in which the symptoms and signs related to diabetes and its complications are perceived. People from India have a common perception the diabetes is caused by excessive consumption of sweets. ${ }^{[11,12]}$ There is also a belief that consuming bitter vegetables or herbs will lower the blood sugar. ${ }^{[13,14]}$ Stress and worry, or genetic or hereditary risk factors for diabetes mellitus are not viewed as significant. However, there could be the urban-rural difference in the influence of environmental factors like stress on diabetes management as a whole. People also believe that smoking and alcohol are not related to diabetes mellitus or its complications. Therefore, for optimum care of people with diabetes, understanding of socio-cultural context is critical as it affects perceptions about how people with diabetes are viewed and supported by their family and how their family.

\section{Culture and dietary beliefs and practices}

Dietary habits and practices are influenced by culture and religion as well as economic conditions. Oil and sugar are considered an integral part of the daily diet in Indian families. Religion is a key aspect of culture that often decides food habits and pattern. Culturally determined dietary practices involve the identification of foods, methods of food preparation, condiment selection, timing and frequency of meals, and the ritual, social, and symbolic use of foods. For example, nonvegetarian diet is not an acceptable food in Hindu communities. Fasting is often practiced by Hindus and Muslims. India is a country with several religious festivals. Sweets and high fat foods are significant components in this festivals and ceremonies. Foods, especially, sweets are shared as gifts with relatives and friends in ceremonies.

Dietary management is one of the most important components for a package of care for people with diabetes. Cultural beliefs are one of the many reasons for nonadherence with dietary recommendations in diabetes. Therefore, care providers' familiarity of these dietary practices is essential for planning culturally appropriate dietary management for persons with diabetes.

\section{Culture and diabetes care seeking behavior}

Disease management decisions are closely linked to cultural background and resources available. ${ }^{[15]}$ Cultural factors influence the access to health care delivery system and the way in which the families interact with health care practitioners ${ }^{[6]}$ Even though, people and community do not consider diabetes as a stigmatized disease, ${ }^{[6,10]}$ many do not regularly participate in diabetes prevention, screening and care programs due to cultural beliefs, different priorities and limited access to services. Low health literacy, lack of knowledge related to diabetes services, misconception about diabetes, lack of family and social support and lack of patients involvement are some of the cultural determinants responsible for poor outcome of diabetes care program. ${ }^{[12]}$ A misbelief that diabetes is the result of divine intervention is often responsible for use of folk medicine leading to delay in care of diabetes until signs and symptoms of some complications emerge. ${ }^{[6,10,12]}$

People with diabetes taking conventional modern medicine (allopathic medication) frequently use folk herbal medicine as home remedies or Ayurvedic medicine, either as supplements or complementary or alternative treatment. ${ }^{[13,15-17]}$ Prayer, acupuncture, massage, hot tub therapy, biofeedback, and yoga have been frequently used by persons with diabetes. ${ }^{[16]}$ Diabetics consuming juices and bitter herbs are not uncommon. ${ }^{[13,14]}$ Desire for early and maximum benefit was the most common reason for using these remedies. ${ }^{[18]}$ Health care providers' understanding of these self-care practices are crucial for modification of treatment strategies and outcome evaluation. In most cases, providers are unaware of the fact that patients are taking Ayurvedic or herbal medication as well. ${ }^{[13]}$ It is important for care providers to be aware that many patients with diabetes may be using complementary medications that may have potential interactions with conventional medicines being used ${ }^{[16]}$ Many of the herbal therapies may be hypoglycemic agents and in combination with conventional treatment of diabetes, may result in hypoglycemic crisis. Moreover, there is inconclusive evidence regarding the usefulness of herbal mediation in the management of type 2 diabetes.

As regards the use of drugs, people feel it is required when there are signs or symptoms of disease or illness. This 
perception of people is the single most important barrier for proper management of diabetes and adherence to treatment. People often judge the severity of an illness by the amount of pain, disability, and discomfort it produces in daily routine activities. ${ }^{[6,10]}$ Therefore, diabetes care providers are often disappointed with diabetes patients for not following up for blood sugar monitoring, early diagnosis and management of complications of diabetes, if any. Provider often feels that, since diabetes is a chronic disease, rural people do not care about the disease and about their health as well. People do not seek health care unless their condition interferes with social or personal activities of daily living, such as work and household maintenance functions. There is often reluctance to seek professional care unless necessary. ${ }^{[19]}$ For adherence to diabetes care, family and social support is vital. Diabetic patients with strong family support are more likely to follow the recommendations of diabetes care providers. ${ }^{[6]}$ All of these factors collectively act as barriers for effective diabetes care. ${ }^{[6,19,20]}$

Culture and communication between people with diabetes and care providers

Languages and local dialects change across cultures and societies and therefore may present as significant barriers in communication. Health literacy is also influenced by cultural beliefs and education, which further influence a person's ability to obtain, interpret, and understand information about health and healthcare services. ${ }^{[21]}$ Compared with persons with diabetes mellitus having adequate health literacy, low health literacy has been associated with poor glycemic control and more risk of diabetes complications. ${ }^{[6]}$

Lack of ability of communicate effectively often results in stress among care providers, poorer client understanding of disease, less recall of information, decreased client satisfaction and premature termination of care. Services of trained interpreter or bilingual family members may be useful in such situations. However, in such situations, an issue of confidentiality needs to be addressed. Culturally specific print materials in patient's primary language may be provided and hence that the information is available to patients, their family members and to other people in their support system. ${ }^{[6,19,21]}$

Familiarity of cultural understanding and communicating effectively is necessary for equal access to services. Therefore, diabetes care providers, to ensure effective communication with persons with diabetes need to present themselves as a colleague, establish ties with family and friends of patients, demonstrate supportive and personalized approach. ${ }^{[6,10,22]}$
Women and diabetes

Women are often are viewed as the custodian of family values and culture. This responsibility to maintain cultural practices and pass them on to younger generations can make it difficult for them to successfully make lifestyle changes leading to poor health outcomes. ${ }^{[23]}$ Nearly, three quarters of women find difficult for follow the care advice by doctors and self-medication is very common in women. ${ }^{[14,23]}$

Furthermore, around $7-17 \%$ of women of child bearing age suffer from gestational diabetes or glucose intolerance during pregnancy. ${ }^{[24,25]}$ Cultural beliefs and practices during pregnancy and overall status of women in family presents as substantial barriers to adhere with providers advice for effective diabetes management. If diabetes during pregnancy is poorly managed, it will harm both the mother and infant. ${ }^{[23]}$

Framework for cultural assessment to plan and deliver cullturally appropriate care

Cultural assessment is a focused and systematic appraisal of beliefs, values, and practices conducted to determine the context and substance of client needs and then to best adapt (or construct) and evaluate health interventions, and with the inculcation of a sense of responsibility in the afflicted individual for self-care. ${ }^{[26,27]}$ Cultural assessment needs to be done at various stages of care and may be focused on those elements relevant to the presenting problem, necessary intervention, and participatory evaluation. ${ }^{[20]}$

\section{CONCLUSION}

Improving diabetes care needs a better understanding of the cultural determinants. To address these issues in prevention and care services, diabetes providers are expected to bear cultural competencies for assessment and planning culturally appropriate interventions. The problem also lies with suggesting a diet regimen which does not fit well with the way people eat in India. Merely following international or Euro-American ways of eating is not the answer, unless the family structure is similar to that which exists in the Euro-American context. More creative ways of talking about diet need to be advised. It is all the more necessary that biomedical practitioners, who will be expected to bear the brunt if and when any public health program for diabetes is introduced, are attuned to the various factors affecting the understanding and treatment of diabetes. Cultural characteristics such as value systems, beliefs, customs, and family patterns may be used as clues for planning culturally appropriate care for diabetes. To deliver these culturally appropriate 
interventions and effective continuum of diabetes care needs innovative models with a multi-disciplinary team, including the lay care giver. These specific interventions, well aligned with local context and needs are likely to have a significant impact on diabetes care. However, such models need to be tested and evaluated.

\section{REFERENCES}

1. King $H$, Aubert RE, Herman WH. Global burden of diabetes, 1995-2025: Prevalence, numerical estimates, and projections. Diabetes Care 1998;21:1414-31.

2. Sicree R, Shaw J, Zimmet P. Diabetes and impaired glucose tolerance. In: Gan D, editor. Diabetes Atlas. International Diabetes Federation. $3^{\text {rd }}$ ed. Belgium: Published by International Diabetes Federation; 2006. p. 15-103.

3. Mohan V, Vassy JL, Pradeepa R, Deepa M, Subashini S. The Indian type 2 diabetes risk score also helps identify those at risk of macrovasvular disease and neuropathy (CURES-77). J Assoc Physicians India 2010;58:430-3.

4. Mohan V, Sandeep S, Deepa R, Shah B, Varghese C. Epidemiology of type 2 diabetes: Indian scenario. Indian J Med Res 2007;125:217-30.

5. Heisler M, Smith DM, Hayward RA, Krein SL, Kerr EA. How well do patients' assessments of their diabetes self-management correlate with actual glycemic control and receipt of recommended diabetes services? Diabetes Care 2003;26:738-43.

6. Tripp-Reimer T, Choi E, Kelley LS, Enslein JC. Cultural barriers to care: Inverting the problem. Diabetes Spectr 2001;14:13-22.

7. Osman A, Curzio J. South Asian cultural concepts in diabetes. Nurs Times 2012;108:28, 30-2.

8. Weiss M. Explanatory model interview catalogue (emic): Framework for comparative study of illness. Transcult Psychiatry 1997;34:235-63.

9. Burnard P. Writing a qualitative research report. Accid Emerg Nurs 2004;12:176-81.

10. Campos $\mathrm{C}$. Narrowing the cultural divide in diabetes mellitus care: A focus on improving cultural competency to better serve hispanic/latino populations. Insulin 2006;1:70-6.

11. Charak Chikitsa Sthana. Ch. 6. Tripathi B, editor. Charaka Samhita of Charaka, Chikitsa Sthana, chapter 15, verse 94-95, 1st ed. Vol. II. Delhi: Chaukhamba Surbharati Prakashan; 2001. p. 1035-6.

12. Alhyas L, McKay A. Socio-cultural aspects of diabetes care: Myths about diabetes in Qassim region, Saudi Arabia. Ann Alquds Med 2010;6:1431.
13. Singh J, Singh R, Gautam CS. Self-medication with herbal remedies amongst patients of type 2 diabetes mellitus: A preliminary study. Indian J Endocrinol Metab 2012;16:662-3.

14. Sushama S, Nandita T. Study on self-medication and self dietmanagement by women of indore city, India. Res J Recent Sci 2012;1:354-6.

15. Chacko E. Culture and therapy: Complementary strategies for the treatment of type-2 diabetes in an urban setting in Kerala, India. Soc Sci Med 2003;56:1087-98.

16. Dham S, Shah V, Hirsch S, Banerji MA. The role of complementary and alternative medicine in diabetes. Curr Diab Rep 2006;6:251-8.

17. Sethi A, Srivastava S, Madhu SV. Prevalence and pattern of use of indigenous medicines in diabetic patients attending a tertiary care centre. J Indian Med Assoc 2011;109:469-71.

18. Mehrotra R, Bajaj S, Kumar D. Use of complementary and alternative medicine by patients with diabetes mellitus. Natl Med J India 2004;17:243-5.

19. Lawton J, Ahmad N, Hallowell N, Hanna L, Douglas M. Perceptions and experiences of taking oral hypoglycaemic agents among people of Pakistani and Indian origin: Qualitative study. BMJ 2005;330:1247.

20. Tripp-Reimer T Cultural assessment. In: Bellack J, Bamford P, editors. Nursing Assessment. A Multidimensional Approach. Monterey, Calif: Wadsworth Health Sciences; 1984. p. 226-46.

21. Greenhalgh T. Barriers to concordance with antidiabetic drugs — cultural differences or human nature? BMJ 2005;330:1250.

22. Lawson B, Van Aarsen K, Latter C, Putnam W, Natarajan N, Burge F. Self-reported health beliefs, lifestyle and health behaviours in community-based patients with diabetes and hypertension. Can J Diabetes 2011;35:490-6.

23. Black SA. Diabetes, diversity, and disparity: What do we do with the evidence? Am J Public Health 2002;92:543-8.

24. Wahi P, Dogra V, Jandial K, Bhagat R, Gupta R, Gupta S, et al. Prevalence of gestational diabetes mellitus (GDM) and its outcomes in Jammu region. J Assoc Physicians India 2011;59:227-30.

25. Seshiah V, Balaji V, Balaji MS, Sanjeevi CB, Green A. Gestational diabetes mellitus in India. J Assoc Physicians India 2004;52:707-11.

26. Guell C. Self-care at the margins: Meals and meters in migrants' diabetes tactics. Med Anthropol Q 2012;26:518-33.

27. Yates-Doerr E. The weight of the self: Care and compassion in Guatemalan dietary choices. Med Anthropol Q 2012;26:136-58.

How to cite this article: Sachdeva S, Khalique N, Ansari MA, Khan Z, Mishra SK, Sharma G. Cultural determinants: Addressing barriers to holistic diabetes care. J Soc Health Diabetes 2015;3:33-8.

Source of Support: Nil. Conflict of Interest: None declared. 